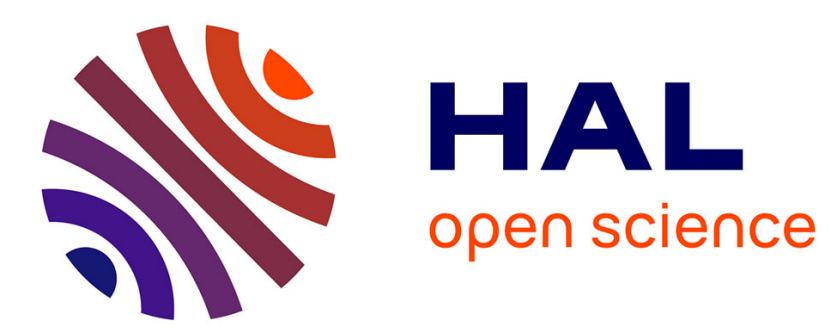

\title{
FESTivE: an information system method to improve product designers and environmental experts information exchanges
}

\author{
Maud Rio, Tatiana Reyes, Lionel Roucoules
}

\section{- To cite this version:}

Maud Rio, Tatiana Reyes, Lionel Roucoules. FESTivE: an information system method to improve product designers and environmental experts information exchanges. Journal of Cleaner Production, 2014, 83, pp.329-340. 10.1016/j.jclepro.2014.07.019 . hal-01084714

\section{HAL Id: hal-01084714 https://hal.science/hal-01084714}

Submitted on 20 Nov 2014

HAL is a multi-disciplinary open access archive for the deposit and dissemination of scientific research documents, whether they are published or not. The documents may come from teaching and research institutions in France or abroad, or from public or private research centers.
L'archive ouverte pluridisciplinaire HAL, est destinée au dépôt et à la diffusion de documents scientifiques de niveau recherche, publiés ou non, émanant des établissements d'enseignement et de recherche français ou étrangers, des laboratoires publics ou privés. 


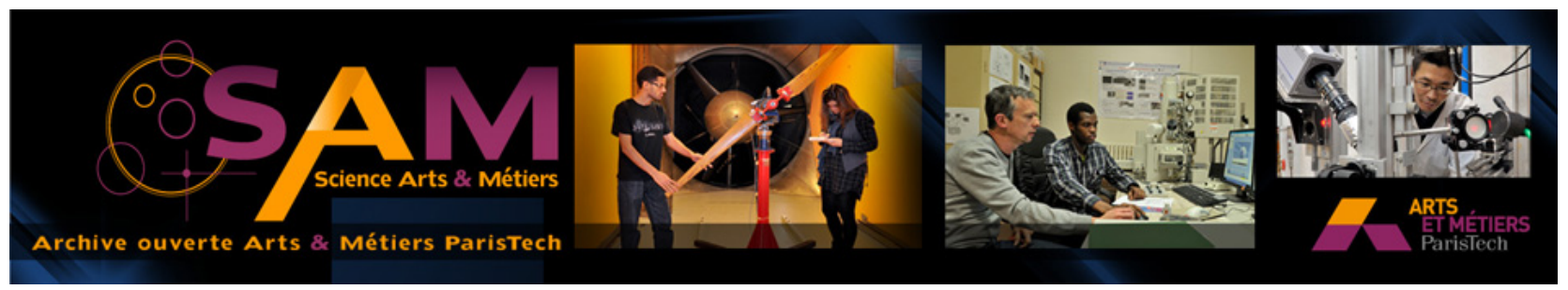

Science Arts \& Métiers (SAM)

is an open access repository that collects the work of Arts et Métiers ParisTech researchers and makes it freely available over the web where possible.

This is an author-deposited version published in: http://sam.ensam.eu

Handle ID: .http://hdl.handle.net/10985/8957

\section{To cite this version :}

Maud RIO, Tatiana REYES, Lionel ROUCOULES - FESTivE: an information system method to improve product designers and environmental experts information exchanges - Journal of Cleaner Production - Vol. 83, p.329-340 - 2014 


\title{
FESTivE: an information system method to improve product designers and environmental experts information exchanges
}

\author{
Maud Rio ${ }^{\mathrm{a}, \mathrm{b},{ }^{*}, \text { Tatiana Reyes }}{ }^{\mathrm{b}}$, Lionel Roucoules ${ }^{\mathrm{c}}$ \\ a School of Architecture and Design, RMIT University, GPO Box 2476, Melbourne VIC 3000, Australia \\ ${ }^{\mathrm{b}}$ University of Technology of Troyes (UTT), ICD-CREIDD, 12 rue Marie Curie, 10004 Troyes, France

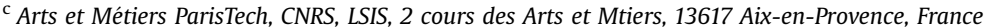

Keywords:

Ecodesign

FESTivE

Interoperability

Collaborative design

\begin{abstract}
A B S T R A C T
Effective collaboration between product designers and environmental experts is an important driver for the ecodesign practice in industry. This paper investigates the principal functions required for such an effective collaboration and aims at facilitating them. Product designers should be able to integrate the environmental parameters into their activities, and to exchange information dynamically with the environmental expert whenever needed during the design process. Therefore, the IT system should be in itself dynamic and flexible to the integration of new concepts (knowledge, software). Recent developments in Model Driven Engineering (MDE) are showing some interesting results to gain flexibility and dynamism in the IT system. Combining software interoperability using model federation based on MDE with the specificity of ecodesign practice in industry this paper proposes the FESTivE method for Federate EcodeSign Tool modEls. Experimented in two different industrial contexts the practical feasibility of FESTivE has been validated with practitioners. Results on the effects of using FESTivE in industry shows that product designers and environmental experts are more equipped to anticipate and to respond to each other's needs at each stage of the design process of product or service.
\end{abstract}

\section{Introduction}

In the current anthropocene era (Crutzen, 2002) human activity contributes to global and irreversible eco-system changes (Rockstrom, 2009). Social pressure such as environmental regulations and customer demands encourages industries to reduce the anthropic invoice generated (Reyes et al., 2007). To do so, the practice of ecodesign seeks to integrate the environmental parameters in the existing design constraints (ISO, 2002). Expected results are environmental impact reduction as well as innovation improvement (Millet, 2003; Wiggum, 2004):

- At the scale of the product designer a partial ecodesign practice focuses on one stage of the life cycle of the product with methods of design for recyclability, for remanufacturing (for instance).

- At the company scale, usual ecodesign practice takes into account all different stages of the product life cycle and is based on

\footnotetext{
* Corresponding author. School of Architecture and Design, RMIT University, Melbourne VIC 3000, Australia. Tel.: +61 39925 3457; fax: +61 399253507. E-mail address: maud.rio@rmit.edu.au (M. Rio).
}

a multi-criteria analysis (multiple impact indicators to avoid burden shifting).

- At the scale of the area and the resources involved in the company activity, ecodesign relies on a systemic approach. The systemic focus contributes to find pathways toward a more sustainable way of living in the society (Morin, 2002): by initiating changes in dominant paradigms (for example regarding energy use (Joore et al., 2012)), such as major and common economical mechanisms (on economy of functionality: (Buclet, 2011a), on industrial ecology: (Erkman, 2002; Buclet, 2011b)).

Comparing the effects of these ecodesign practices Millet (2003) (Millet, 2003) shows that ecodesigning in a system-based reasoning has the highest improvement potential. The ecodesign practice is connected to the scale of the company and the area where it is implemented. Literature study shows that such a connection can be supported by methods and tools. For instance Zhang et al. (2013) (Zhang et al., 2013) proposes a three layer tool combining the strategy of the company with the tactic of product managers (e.g. manufacturing department), and with the product designer activities (e.g. Computer Aided Design (CAD) and Computer Aided Process Planning (CAPP)). Considering this system, this 
paper focuses on the collaboration between product designers and environmental experts. At their scale, their aim is to practice ecodesign together to globally minimise environmental impacts of the product (or service) they are designing.

The conceptual framework of this paper is therefore the process of designing a product from the early design stage, to the detailed design stage (Pahl and Beitz, 1996). During the design process, product designers with different expertise (technology, material, mechanical design, ergonomic, etc.) share their resources to reach a common goal, i.e. to design a product that fulfills the technical, economic and environmental specifications. Each expert, commonly referred to in this article as a product designer, defines and values his own parameters that are complementary, and are related to the other expert's parameters in a collaborative way (Roucoules and Tichkiewitch, 2000). Taking into account the environmental parameters when designing requires managing the collateral impacts of the different design choices taken by all product designers in a transversal (i.e. global) life cycle perspective of the product (Rio et al., 2013). This can be supported by global and expert environmental assessments methods. These methods are supported by tools varying along the design process (Lewandowska and Kurczewski, 2010): from creativity tools in the early stages (Tyl et al., 2010), to full life cycle assessment tools (LCA (ISO, 2006a), (ISO, 2006b)) at the detailed design stages. However because of the level of expertise involved in the task, ecodesign expert tools require environmental experts to use them (Vallet et al., 2010a)). These tools require that users have access to all available information about the product within the design process stages, from the various product design activities involved (and supports) (Vallet et al., 2010b). Considering that information and software are constantly evolving during the design process, agile design process are more and more used to develop software iteratively and incrementally as a flexible response to needs (e.g. new tool, new constraints) (Highsmith and Cockburn, 2001).

In this contextual framework, the research question of this paper is how to support the collaboration between product designers and environmental experts during agile design process.

This question highlights three principal functions that need investigation (1):

- The function of integration of the environmental dimension in the product designer's activities, i.e. linking the product designers' parameters to the environmental experts' parameters. For example, the mass, the type of material, the shape of the product designed, the manufacturing process needed to produce the product, the product supply chain involved, the type of technology supporting the delivery of the products' functions during the use stage, its end of life (etc.) are example of designers' parameters that are used by the environmental expert to model the material and energy flows involved in this future life cycle process, and model the potential environmental impacts that could be generated, such as resource scarcity, biodiversity loss, climate change, ozone layer depletion, eco-toxicity.

- The contextual function: supporting collaboration within various contexts of ecodesign practices, e.g. early design vs. detailed design, technology involved, type of project, expertise involved, industry sector (textile, heavy industry, electronic, etc.). For example, the environmental analysis in the early design stage as well as the tool needed for its support may differ from the environmental analysis performed when design choices are settled. The interaction between product designers and environmental experts would also vary. Another example is the availability of environmental data from one industrial sector to another (e.g. using nanotube particles in a urban design shirt in the textile industry may require some specific inventory data and environmental assessment models that would not be available to environmental experts).

- The technical function of supporting information exchanges between product designers' tools (e.g. Computer Aided Design (CAD), material choice, logistic, industrial design tools) and transversal global environmental tools (e.g. LCA). Those tools are complementary but different (semantic, data format). For example, transferring information about product designers' parameter to the environmental expert may be technically supported by a product data management system. Whereas the transfer of environmental results to product designer interested by the effect of their design choices may be only possible by email or verbally.

This paper firstly investigates the limits and opportunities of these three research functions in relation to scientific literature leading to three major issues (descriptive study 1 ). Then, a proposition of method is given (prescriptive study) and validated by industrial case studies, empirical studies and research action by interview and discussion (descriptive study 2). The paper concludes with the contribution of this proposition to the initial research question.

Justification of the research method. Alternating descriptive and prescriptive studies is a research method given by Blessing and Chakrabarti (Blessing and Chakrabarti, 2009) called the Design Research Methodology (DRM). The DRM is adapted to the design research that aims at understanding and improving the design practices (Hubka and Eder, 1996) (Pahl and Beitz, 1996). Design and particularly ecodesign is transdisciplinary and research in this domain is relatively young (since 1960 approximately and 1985 for ecodesign). Based on literature studies, DRM has been proposed to support design scientific rigor of researchers in this domain and help them federate a common design research vision (Blessing and Chakrabarti, 2009). Research in ecodesign mainly experiments on industries and DRM creates a space to use complementary tools and methods that contribute to applying research outputs to industries.

\section{Opportunities and limits of research functions to support a collaborative (eco)design process}

\subsection{Integration of environmental parameters into product designers' parameters}

One angle to study the integration of environmental dimension into product designers' activities is to consider:

- Compatible environmental and product design objectives (Brissaud et al., 2006).

- The importance of environmental integration as early as possible during the design process (Dewulf, 2003) (Duflou et al., 2003).

- The environmental knowledge needed to perform ecodesign (Lozano Garca et al., 2006).

These three aspects are presented below.

The life cycle perspective in ecodesign. First, there is a lack of common definition of life cycle visions within product designer activities (Brissaud et al., 2006). For example, the marketing life cycle definition differs from the mechanical product design definition. Environmental experts will have a specific idea of the life cycle of the product due to their own practice in Life Cycle Assessment (LCA). Second, there is a lack of common objectives between product designers and environmental experts during the design process. For instance a product designer designing a part will focus on choosing the right materials offering the mechanical properties that meet the required mechanical specifications. The 
parameter used to meet those specifications could deal for instance with materials' yield strength, ultimate strength, density, etc. For the same part and for a given material, the environmental expert would rather focus on the embodied energy of the chosen material, the material density (i.e. mass of the part), or its end-of-life properties. Each would give a different order of importance to each property of the material. Therefore, product managers and environmental experts should agree on compatible objectives regarding techno-economic and environmental aspects of the product being designed. Multi-criteria decision making supports are already used in industry to establish hierarchy between product designs' specifications in early design stages (for instance (Saaty, 1980)). From clear and compatible objectives the order of importance of the product specification items including environmental criteria should be transparent. This would allow product designers and environmental experts to defend their own expert advice in a fair way.

A collaborative process. Environmental knowledge is increasingly common in product designer curriculum vitae (Lozano Garca et al., 2006). This should help product designers to partially integrate environmental considerations in their practices, and to understand the role of the environmental expert (Riel et al., 2010). However, the ratio of common environmental knowledge between an environmental expert and a product designer is hard to define, to reach an effective communication between product designer and environmental expert (Vallet et al., 2013). The information communicated needs to be expressed in such a way that keeps the same meaning within the semantic context of the person that receives it. Even if the communication is effective, the environmental integration might be partial; since general environmental knowledge does not necessarily mean that the product designer understands the potential influence that his design parameters can create on environmental parameters. Therefore, there is a need to create a causeto-effect link between environmental parameters and the other technico-economical parameters involved in each expert activity. This link is situated at the interface between product designer activities and environmental expert activities. The understanding of this link is anchored in each activity. Integration is about understanding this link and being able to compose with the information that it brings.

The integration issue. This literature review highlighted a major issue, called in this research the integration issue. This issue limits product designers' chance to fully integrate the environmental dimension in their practices because of confusion between global and local environmental objectives and matching these with their design expectations and knowledge. This issue points out an existing breakdown in semantic and cause-to-effect links between environmental and product designer parameters. This integration issue raises the question of the tools and methods used when practicing ecodesign: are they adapted to the contexts of practitioners?

\subsection{Adaptation of different contexts of ecodesign practices}

The second function raised by the research question is linked to the capacity of the collaborative system between product designers and environment experts to adapt to the various contexts of the ecodesign practice. As seen previously, ecodesign practice is supported by methods and tools. They are developed by researchers and industrial practitioners (for instance (Navarro et al., 2005) (Kota and Chakrabarti, 2007)). They are developed to be used in a specific context, and to fulfill a specific need. This need can be the adaptation: to a product designer tool and knowledge, to a specific stage of the design process (preliminary design, detailed design, prototype, etc.), to an industrial sector (e.g. packaging, textile, electronic devices, car industry), to the environmental management strategy of the company, to unify practices (standards), etc. Therefore, numerous contexts of ecodesign practice are covered based on each different industries' culture: technology, product, process stage, knowledge required, etc. However, observations from industrial practices show that there is a lack of contextual classification of those supports made by and for the company (Rio et al., 2011). As a result, it is generally hard and time consuming for the company to find the proper support while dealing with specific demands in different contexts of their ecodesign practice. This unfulfilled function is called in this article the contextual issue.

Existing ecodesign supports that should be used in line with the context of the ecodesign practice of the company raises the question of their capacity to exchange information with existing tools in the company, such as for instance product designer tools (CAD, CAPP), product manager tools as Product Life Cycle Management software (PLM) and Enterprise Resources Planning tools (ERP).

\subsection{Ensuring information exchanges between product designers' tools and environmental experts' tools}

Gathering information from the whole product life cycle during the design process is critical when assessing the environmental performance of different concepts or design choices being made. Information might be available to a product designer, but not necessarily transferable to the environmental expert software. One possible reason could be the incapacity of the two (or more) programs to understand, to process, or to exchange this information. Interoperability between different tools signifies that they have the capacity to exchange and use the information from each other. In each tool, the information is managed within its related semantic concepts.

To facilitate information exchanges during the design process, interoperability between product designer software and environmental assessment software is an increasing focus of engineering software developers. For example:

- The integration of streamlined LCA software into a Computer Aided Design software, e.g. SolidWork sustainability module, from Dassault Systems group (Mathieux and et al., 2005);

- The development of environmental platforms linking PLM to LCA software, e.g. ENOVIA from Dassault Systems Group (Theret et al., 2011).

On the one hand, integrating ecodesign software into product designer software is not adapted to the ideal of complementary experts that collaborate during the agile design process (first example) (Rio et al., 2013). Agile design processes are supposed to deliver software structural flexibility, which is not the case when integrating a quasi-independent module in an existing software. On the other hand, the development of integrative platforms (Theret et al., 2011) facing challenges in managing the variety of semantic concepts and the relationship between those concepts. In practice it is difficult to support the information feedback from the environmental assessment activity to the product designer activities (Rio et al., 2013). This does not ease, or allow, information exchanges between those activities, in both direction (i.e. no dynamic exchanges). The number of problems still remaining to achieve environmental software and product designer software tools interoperability is called in this paper the technical issue.

\subsection{Sum-up of research issues and research hypothesis}

In regard to supporting collaboration between product designers and environmental experts during the product design 
process, the literature review has investigated three functions. First, environmental integration in product designer activities requires:

- Product managers and environmental experts sharing a common design goal and agreeing on compatible design requirements for the product being developed;

- Product designers and environmental experts sharing a minimum of environmental knowledge, supporting the link between the environmental parameters and the product design parameters as early as possible, and continuously during the design process.

The integration issue refers to the existing confusion between environmental and product design objectives and the breakdown in semantic links and cause-to-effect link between environmental and product designer parameters that alter the integration function.

The second function is the contextual adaptation needed to perform ecodesign. The deployment of an ecodesign practice requires:

- Tools and methods to be adapted to the design contexts of when, where, what and by who ecodesign is performed;

- A variety of environmental tools to be used continuously across local product designer activities and transversal environmental activities.

Literature studies showed that there is a lack of environmental tools and methods library, ranked by contextual criterion, available to companies, and used by them - the contextual issue.

Third, the integration and contextual functions needed when performing ecodesign require that the information system offers a structural flexibility, and facilitates dynamic information exchanges between different tools where data are linked to different semantics.

However, the study of currently available software on the market shows that the information system struggles to adapt itself dynamically and with flexibility to various and complementary tools that are needed to perform ecodesign. The technical issue refers to this lack of structural flexibility and dynamisms provided.

The hypothesis of this research is that the integration, contextual and technical issues can be countered by using model federation based on Model Driven Engineering (MDE) or Model Based Engineering (MBE).

\section{Proposition: the FESTivE method based on models federation}

\subsection{Introduction to models federation}

In this paper, a model refers to a model of data. A model is a representation of a real system, which captures some of its characteristics. In a design process, there are different models for different product designers' support (e.g. software). A model has a specific syntax (textual or graphical notation which corresponds to a specific language) and also specific semantic related to its concepts and structure. In MDE, the product model or system model refers to the structure supporting the organisation, the collection, and the traceability of the knowledge associated to the product. Models allow software to conduct automatic reasoning and share data with other software. In the context of design, product designers and environmental experts are using different models due to the different supports used to run their proper product assessment. The model structure and the language in which the model is expressed (syntactic rules) are defined in a meta-model. A meta- model is therefore seen as a model describing the model (Favre et al., 2006).

Environmental parameters are defined in this paper as information about the product that has an effect on its global environmental performance (e.g. materials, mass, manufacturing and assembly technologies, suppliers, functions). Such information can be expressed through models. In theory, three types of interoperability exist: the integration, the unification and the federation of models (ISO, 1998). The following section investigates which type of interoperability is adapted to exchange environmental parameters between product designers and environmental experts.

- Integration: all models are based on a unique meta-model. The meta-model defines the structure of the data in the model.

As shown in Rio et al. (2013), the information system based on model integration signifies that a unique structure of data exists that is common to all ecodesign supports. Considering the variety of methods and tools covering various ecodesign contexts, integration is not a plausible way to ensure data exchanges between product designers and environmental experts.

- Unification: the relationships between each different models are based on a meta-model (named mediator, or pivot).

A current example of unification is the Standard for the Exchange of Product Model Data (STEP) that is currently used in Computer Aided Software (CAD) to exchange data about the product geometry. Unification is adapted to models where data are shared and common. This could be used for standardized LCA software based on the Bill of Material of the product (BOM). However, the standard will have to be adapted to new concepts. This standard would not support much the evolution of the tools for new contexts. Considering that new types of tools continue to emerge, unification is not an adapted solution to cover the variety of context when practicing ecodesign in agile design process.

- Federation: models are based on different meta-models, forming meta-models networks that are linked with each other.

Federation is flexible to new concept introduction (i.e. new ecodesign tool). Each different model is based on the meta-model that corresponds to their expert tool. The data are therefore expressed in their full semantic context, which give them more sense (data become information). Those models will be able to federate their contents, if some relationships between the corresponding meta-models are defined. This can be supported by Model Driven Engineering (MDE) (Iraqi-Houssaini et al., 2011; Iraqi et al., 2012).

Considering the pros. and cons. raised by integration, unification and federation, this research proposes to use federation that best answers to the technical issue presented in this paper. The proposal suggests federating different models using MDE as a major assumption of this research.

\subsection{Model federation based on model driven engineering}

Models are federated when some relationships are established among Meta-Models to instantiate dynamically the different models. MDE comprises a set of modeling methods based on models that are suitable to define this relationship. In MDE, this relationship is described using transformation rules, and then coded (mapping). In this paper, to make it easier to understand, metamodel transformations are called knowledge transformations. Knowledge refers to the semantic context of each Meta-Model. 
Semantic concepts need to be understood to define those transformations.

When the knowledge transformation is defined, the real data transformation can occur (in the real world). By projection into the model level, the knowledge transformations allow some of the models involved to inject some of their contents (data) into other models involved. Those data will then be naturally used by the software, because the semantic contexts are coherent. Dealing with the meta-model level of abstraction means that the projection of the meta-model in the real world will generate data that can be based on different semantic (expertise context).

Research results show some benefits of using MBE in product design (Iraqi and Roucoules, 2013). First, MBE allows management of the relationships between models, which are independent of product design experts' tools. The transfer from product designers' tool to another is facilitated. The transformation among semantic models is enriched by the flexibility related to the modelling languages used. Second, MBE allows the Information Technology (IT) system to be dynamically implemented for a specific design process. The IT system gains modularity as it is possible to define knowledge transformations at a particularity thin granularity level (only some part of meta-models can be taken into account) (Iraqi et al., 2012). In addition, the transformations can be coded in a heterogeneous manner. For instance, developers can use different coding languages and code different transformation in different time frames. This offers IT developers the possibility to implement the IT system incrementally, little by little and when it is needed.

Those reasons makes model federation based on MDE a flexible and dynamic solution adapted to IT developers in industry for supporting the integration of environmental parameters into product designer activities, and for allowing new ecodesign tools to be used and to interoperate with existing product designer tools.

\subsection{Research proposal: the FESTivE method: Federate EcodeSign Tools modEls method}

The FESTivE method, Federate EcodeSign Tools modEls, has been developed in this research to use model federation based on MDE in the specific context of ecodesign practice in industry. The FESTivE method is based on the three steps method presented and illustrated in Fig. 1:

1. Modeling the design process;

2. Modeling the data involved in activities;

3. Modeling the knowledge transformations involved when exchanging information between activities.
- Stage A: The use of the FESTivE three step method: creating the library of meta-models of tools and methods related to product design and ecodesign, as well as building the knowledge transformation models between those metamodels;

- Stage B: Monitoring results of the application of the three step FESTivE method: analysing the context and effects of using the library during the product design process to support information exchanges when performing ecodesign.

Fig. 2 presents the Stage A and B proposed in this paper.

In MDE, a knowledge transformation is established between at least one target meta-model and one source meta-model. Therefore, stage A firstly consists in the definitions of target and source meta-models. Secondly, the knowledge transformation between those meta-models is defined. To identify the meta-models involved in the design process and their links, FESTivE proposes to model the links between the activities of product designers and environmental experts. This can be supported by different modelling language for design process modelling, such as the activity diagrams in Unified Modelling Language (UML). From those activities, tools and methods used by product designers are studied to describe the data they use as input and the data they create as output. Knowing the data input and output and their semantics and formats allows their related meta-models to be defined.

The links between those meta-models are also identified by the activity diagram. Each link is modelled by a knowledge transformation. Useful transformation rules when dealing with environmental parameters are available (allocation, database equivalence, calculation) (Rio et al., 2013). They are used to define transformation knowledge.

The meta-models and knowledge transformations associated with each tool or method are ranked by contextual need into a library. Ranking criterion can be for instance:

- Stage of the design process when the tool is needed (early design stage, preliminary, detailed design, prototype);

- Level of expertise required and in which domain (expert tool for environmental practitioners, streamlined tool for mechanical engineering designer, etc.);

- Type of product or service designed appropriate for the tool or method (electronic device, mechanical component, textile, furniture, etc.);

- Any other relevant criteria specific to the company.

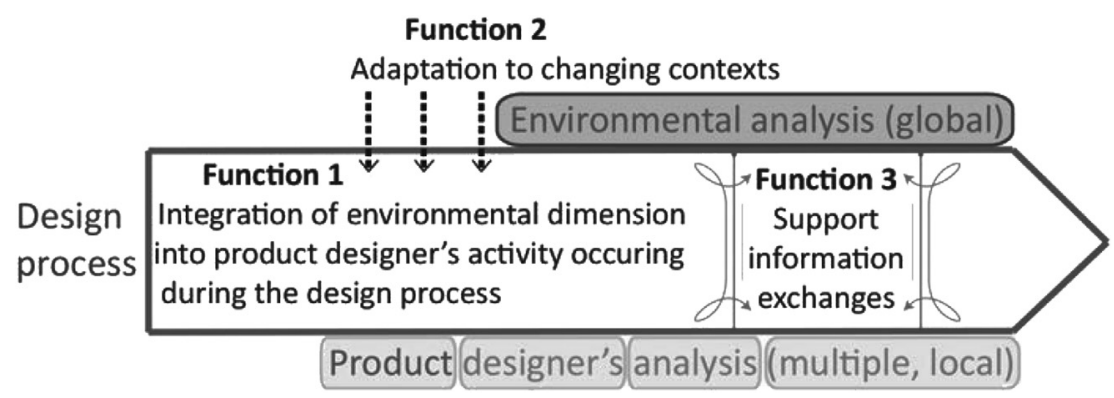

Fig. 1. Schematic presentation of the functions highlighted to support product designers and environmental expert collaboration.

The proposition made in this paper is firstly to follow the three steps of the FESTivE method. Secondly, the proposition seeks to monitor effects of using the FESTivE method results in an industrial context. The whole process is presented through two major stages summarised as follow:
The company enriches its library little by little, capitalising on its previous experiences. Ideally, those meta-models and knowledge transformations could be shared between companies (Rio et al., 2013). Confidentiality issues can be set aside, as meta-models do not involve data, they are situated at a superior level of abstraction. 
Stage A: Application of the FESTiVE method

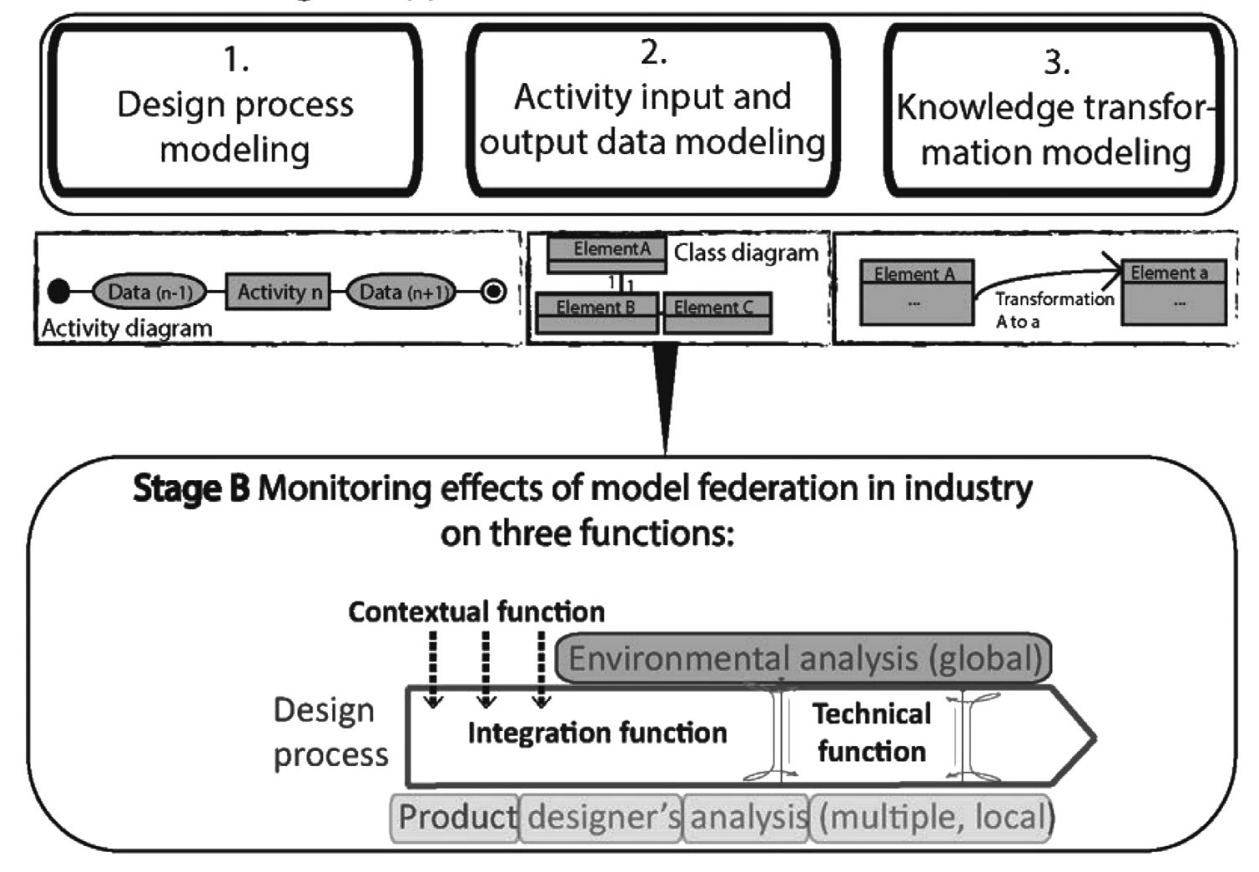

Fig. 2. Application and monitoring effects of the FESTivE method in industry from (Rio et al., 2013).

Stage B consists in deploying the design process by linking up the information exchanges between the meta-models involved. Those information links are from:

- One to one: one source meta-model linked to one target meta-model. The knowledge transformation can be based on databases equivalence between the source and the target models created by the source and target meta-models for instance.

- $n$ to one: several source meta-models linked together to the target meta-model. A possible knowledge transformation could be based on several calculations involving several parts of the different source meta-model.

Source and target meta-models, and knowledge transformations previously created are taken from the library. Each meta-model and model from the library relate to the specific tools used by product designers and environmental expert. Ranking the models by contextual needs helps to anticipate the future tool deployment when planning the design process in the early design stages. Therefore the library supports product managers to manage resources in a transparent way. It also presents the links between those tools and other product designer tools, allowing product managers to create in advance scenarios of resources deployment during the design process. As presented by Zhang et al. (2013) the application of FESTivE is ideally linked with the tactic and the strategy of the company regarding sustainability, involving other methods.

The validation method proposed in this paper is presented in the following sub-section.

\subsection{Validation method: the effect of FESTivE during design}

The ultimate benefits of having used the FESTivE method for an industry would be to have improved collaboration between product designers and environmental experts during the design process within the various contexts of design. The improvements tackled by the proposed method are regarding technical, contextual and integration functions presented in section 2. The hypothesis of this research stands on the idea that when those three functions are satisfied, collaboration should be eased.

A number of criteria have been established to validate:

- The practical feasibility in industry of the FESTivE method (i.e. when using FESTivE).

- The ability of the method to improve those three functions (a posteriori). Therefore, the potential improvements regarding product designer and environmental expert collaboration (proactivity).

The links between the technical, contextual and integration functions and the validation criteria chosen are presented Fig. 3. As presented in this figure, the practical feasibility of FESTivE in industry have been chosen to be evaluated through:

- the capacity of the IT systems (software) to be implemented;

- the time spent for IT developments and costs associated;

- the consistency between the IT tools and the needs of product designers and environmental experts;

- the capacity to co-develop the models and easily update them regarding needs;

- the ability of the code used for the developments to be modular and developed little by little (incrementally);

Those criteria are indeed intrinsic to agile software developments (Highsmith and Cockburn, 2001).

The second validation concerns the ability of the method to improve those three functions ( $a$ posteriori). Once FESTivE has been used, this is proposed to be evaluated through:

- the practicability of the information exchanges provided, in terms of integration and ergonomic aspects; 
How to support collaboration between product designers and the environmental expert during the design process within various contexts?

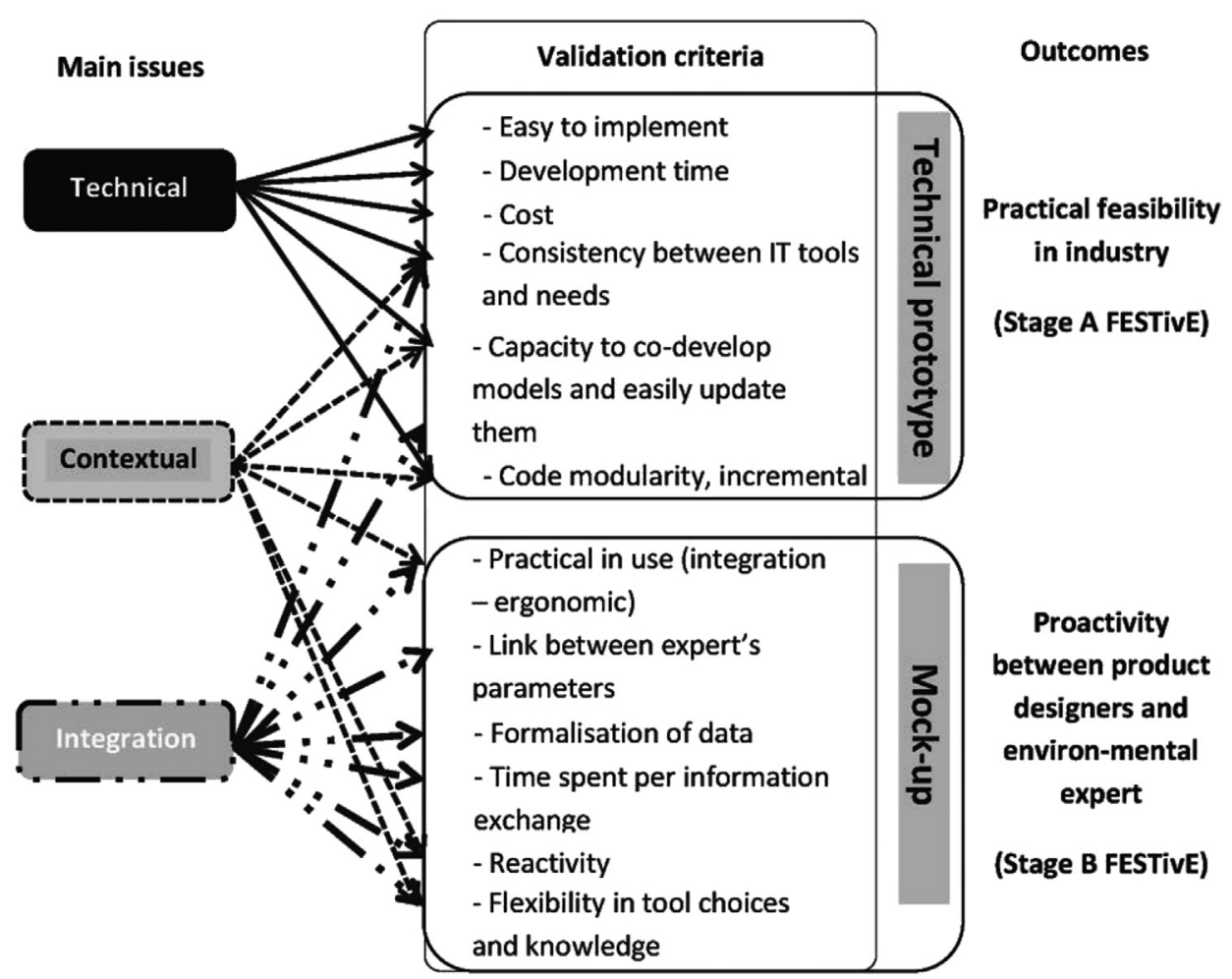

Fig. 3. Validation criteria.

- the links established between product designers' parameters and environmental experts' parameters;

- some useful data that has been formalised in the models;

- the time spent per information exchange;

- the capacity of product designers and environmental experts to be reactive regarding each other demands;

- the capacity of product designers and environmental experts to chose and exchange informations through different tools and that are aligned with their knowledge.

The next section presents the trial of stages A and B of the FESTivE method on two industrial case studies. The validation criteria has been applied to those two case studies.

\section{Application on industrial case studies}

\subsection{Case study procedure and timelines}

Presentation. The FESTivE method has been tested through two complementary case studies. The first case study was conducted in the company Parkeon over 24 months of interaction with staff members from the product development department, including IT developers. The second case study was conducted with Quiksilver over 18 months, ran in collaboration with two other research centres in France and one institute (IFTH for Institut Francais du Textile et de l'Habillement), and involved two full time researchers.

Both case studies have two stages:
- First step testing stage A (application of FESTivE three steps method, $c f$. Table 1).

- Second step testing stage B (monitoring the effects of FESTivE, $c f$. Table 2)

Each case study seeks to demonstrate complementary aspects of both stages. The Parkeon case study was firstly run to demonstrate the practical feasibility of model federation based on MDE in the case of an ecodesign process using FESTivE. This case is therefore focused on the technical aspects of the method (Stage A and B) in industry. The output is a prototype of model federation specific to the context of Parkeon. Complementary, the Quiksilver case study seeks to demonstrate the feasibility of this method in a different industrial context. The Parkeon case study involved the development of electronic devices, whereas the process development studied through Quiksilver involved clothes production from the textile sector. The Quiksilver case study output is a mock-up of the design process involving information exchanges based on model federation that has been used in practice to demonstrate the ability of the method to be used in different ecodesign contexts and its capacity to be integrated in various product designer and environmental expert activities.

The validation criteria are presented in Fig. 3.

Stage A: testing with industries the three stages of the FESTivE method, Table 1. FESTivE method stage A is composed of the three steps that have been tested twice through Parkeon and Quiksilver case studies: 
Table 1

Case study testing stage A (technical feasibility of the three steps of the FESTivE method).

\begin{tabular}{|c|c|c|}
\hline $\begin{array}{l}\text { Procedure followed for stage } \\
\text { A: building meta-model }\end{array}$ & Parkeon case study & Quiksilver case study \\
\hline 1.Creation of the activity diagram & $\begin{array}{l}\text { Person involved: } 10 \text { interviews Product designers, IT Developers } \\
\text { technology, Environmental experts } \\
\text { Support used: survey Questionnaire One to one interviews } \\
\text { Timeline: } 1-2 \mathrm{H} \text { per person } 10 \text { days on site }\end{array}$ & $\begin{array}{l}\text { Person involved: } 28 \text { interviews A representative } \\
\text { for each expertise Collaboration with } 3 \text { researcher } \\
\text { Support used: survey Questionnaire One to one } \\
\text { interviews Timeline: } 1-2 \mathrm{H} \text { per person } 15 \text { days on site }\end{array}$ \\
\hline 2.Creation of meta-models & Person involved: IT developer from research centre & Person involved: IT developer from research centre \\
\hline $\begin{array}{l}\text { 3.Creation of transformation models } \\
\text { Coding transformations }\end{array}$ & Support: Eclipse Timeline: 12 months & Support: Prezi, Eclipse Timeline: 6 months \\
\hline Outcomes & Prototype: a technical Demonstrator of FESTivE method & $\begin{array}{l}\text { Cartographies and mock-up of the whole company, } \\
\text { Complementary IT develop-ments based on model } \\
\text { federation }\end{array}$ \\
\hline
\end{tabular}

Table 2

Case study testing stage B (effect of using FESTivE in industries).

\begin{tabular}{|c|c|c|}
\hline $\begin{array}{l}\text { Procedure followed for stage B: } \\
\text { FESTivE in practice }\end{array}$ & Parkeon case study & Quiksilver case study \\
\hline 1.Identification of tools and knowledge & $\begin{array}{l}\text { Person involved: } 5 \text { interviews } \\
2 \text { Product Designers, } \\
2 \text { Product Manager } \\
1 \text { Environmental expert }\end{array}$ & $\begin{array}{l}\text { Person involved: } 5 \text { interviews } \\
2 \text { Designer and Stylist } \\
1 \text { Product Manager } \\
1 \text { Collection Technician } \\
1 \text { Environmental expert }\end{array}$ \\
\hline 2.Product process deployment & $\begin{array}{l}\text { Support used: Interviews } \\
\text { One to one discussion } \\
\text { Feedback } \\
\text { Timeline: } 10 \text { days of work } \\
12 \text { months of development }\end{array}$ & $\begin{array}{l}\text { Support used: Interviews } \\
\text { one to one discussion } \\
\text { Feedback } \\
\text { Timeline: } 10 \text { days of work } \\
12 \text { months of development }\end{array}$ \\
\hline Outcomes & $\begin{array}{l}\text { Mock-up, IT implementations with } \\
\text { model federation, improved by product } \\
\text { designer and environmental expert feedback }\end{array}$ & $\begin{array}{l}\text { Specification of an 'operational' module } \\
\text { to improve information exchanges between } \\
\text { product designers and environmental experts during design }\end{array}$ \\
\hline
\end{tabular}

- Step 1 creation of the activity diagram.

Parkeon case study: was based on interviews with 10 staff members over 10 days. Four product designers (mechanical engineering, material, electronic), two IT developers, one technology expert and three environmental experts from the company were interviewed. Each one-to-one interview lasted between 1 and $2 \mathrm{~h}$ and was based on a questionnaire with open questions aimed at making the interviewee describe his activities, the tools and supports he uses, the information he creates, the information he needs to run his activities, and the type of interaction he has with his colleagues during the design process.

Quiksilver case study: was based on interviews with 28 staff members, covering one representative for each expertise at the company: from the top management board to the technician during product design. The survey was conducted in collaboration with 3 researchers. Each interview lasted between 1 and $2 \mathrm{~h}$ and was based on a questionnaire, comprising open questions to elicit descriptions of the activities of the company, the main tools and supports involved, the links between activities and the type of information circulating between activities. This step involved 15 days on site.

- Step 2, and 3: creation of the meta-models, creation of the knowledge transformation models and coding the transformations.

Parkeon case study: was conducted on a period of 12 months by one researcher in collaboration with one IT developer from the LSIS $^{1}$ research centre. During this period, all the information from

\footnotetext{
${ }^{1}$ Research centre website: www.lsis.org, December 2013.
}

the first step were analysed and modeled in laboratory using the Eclipse Modeling Framework (EMF).

Quiksilver case study: was conducted over a 6 month period by three researchers in collaboration with one IT developer from the research centre. All data gathered from the first step had been analysed and modeled through a system diagram, or cartography (supported by Prezi online software). Then developers and the researcher have developed models using Eclipse modeling software.

- Outcomes: the Parkeon case study delivered a technical demonstrator of the FESTivE method at the end of this process. The activity diagram and some of the meta-models and knowledge transformation modeled have been published in Rio et al., 2013.

The Quiksilver case study delivered cartography of the interaction between activities involved in Quiksilver during the design process of a new clothing collection. This systemic mock-up also contains examples of IT developments based on model federation occurring during the design process between collection technician, stylists and designers.

Stage B: testing the effect of using the FESTivE method in industry.

- Step 1 and 2: identification of tools needed by product designers and deployment of the design process (Table 2).

During stage B, outcomes from stage A were used to support of discussion of testing the effect of FESTivE. In both industrial case studies (Parkeon and Quiksilver), 5 semi-directed interviews based on one to one discussion were conducted, involving:

- 2 product designers, 2 product manager and 1 environmental expert (Parkeon); 
- 2 industrial designers and stylists, 1 product manager, 1 collection technician and 1 environmental expert (Quiksilver).

Parkeon case study: was conducted in the following 12 months after the end of Parkeons' stage A. The technical demonstrator (i.e. prototype) was used to show a virtual situation of what would be the collaboration situation of the interviewed if model federation was implemented in the IT system of his company. Discussions with users aimed to assess technical, contextual and integration issues in the virtually changed situation. The assessment is based on the validation criteria presented in the following section.

Quiksilver case study was similarly conducted during a period of 12 months after the end of Quiksilvers' stage A. Mappings and mock-ups of activities and interactions occurring during the design process and implemented by model federation were presented to the interviewees. The aim of the semi-directed interview was to gather feedback about technical, contextual and integration issues faced by them in a typical design situation.

- The outcomes: stage A mock-up and IT system implementations with model federation have been improved by the assessments results and product designers and environmental experts' feedback given at the end of this stage. The entire Quiksilver case study (stages A and B) led to the specification of the socalled operational layer published in Zhang et al. (2013). This module aims to support information exchanges between product designers and environmental experts based on model federation (using FESTivE). The potential information exchange improvement is measured by indicators that have effects on tactical and strategic level indicators in the company regarding environmental aspects.

\subsection{Validation criterion of FESTivE and demonstrator}

Validation of this research is experimental (Barth et al., 2011). The validation is based on facts, through discussion and research-action. Interviews based on questionnaires used Likert scales, which allowed interviewees to specify their level of agreement or disagreement to the statement on a symmetric agree-disagree scale.

Considering that the research question of this paper is how to support the collaboration between product designers and environmental expert during agile design process, section 2 has highlighted three issues: the technical, contextual and integration issues. To assess those three issues, participants of the case studies were interviewed before and after the use of FESTivE with the same series of questions. Each question is related to one or more validation criterion relating to the issues considered. The relationship between the validation criterion and the issues is presented in Fig. 3. The technical prototype and the mock-up were used to present the situation after having used the FESTivE method. The prototype and the mock-up were developed with the participants after the first interview to take into account their needs, which involved technical, integration and contextual aspects.

To assess the technical issue interviews aimed to ask IT developers various questions: are models (meta-models and transformation) easy to implement? Is the development time consuming and costing? Are the developer tools providing the right support regarding the interoperability needs? Is it easy to make the model evolve with the evolution of product designer and environmental expert needs? Are product designers and IT developers equipped to co-develop interoperability between tools together? Is the code offering modularity? Regarding the code, is it possible to incrementally develop effective information exchanges between tools?
The contextual issue also concerns IT developers, as they have to maintain an efficient information system in the company. In practice, during the design process it is mainly product designers and environmental experts that are dealing with the ability to find the right tool and method for designing a product that meets all requirements, including environmental ones (e.g. environmental performance on few impact indicators such as resource scarcity, biodiversity loss, climate change, ozone layer depletion, ecotoxicity). Therefore, product designers and IT developers were asked the following questions: are tools practical in use in terms of ergonomic and integration within their activities when designing? When dealing with environmental parameters, is it possible to react to a specific demand? Does the IT system offer a large spectrum of tools that are adapted to your knowledge? Is the IT system flexible to the introduction of a new tool that would better suit you during design?

The third series of question are related to integration: the capacity of tools to be integrated into designers activities, linking specific product designer parameters with environmental parameters. This issue concerns product designers and environmental expert, and sometimes IT developers. For instance, in Parkeon case study some product designers had part of their time devoted to IT developments. This is a common in Small and Medium size Enterprises (SME) where hiring a full expert for doing a specific task might be too expensive. The following questions were asked to product designers and environmental experts: is there a link between your parameters and product designer parameters or environmental expert parameters? Is the data that you use formalised, or expressed in a certain way that you share with other? Is it fast and easy to exchange information that is important regarding the product specifications? Is it easy to use a new tool and exchange with others the information created?

\subsection{Case studies results: observation made before FESTivE}

Survey of the studied design process involving 10 persons in this company (stage A, Table 1) showed some issues regarding the integration, contextual and technical functions presented in Section 2:

- Contextual: the project manager encourages designers from different expertise to decide for their own expertise. A multicriteria matrix is used since the early design stages to take into account all design specifications at the same level. Informal meeting are organised on a regular basis to discuss about design specifications and synchronise design choices. Frequent information exchanges are occurring between the different experts by email, using tables for instance.

- Environmental integration: environmental criterion are integrated in the product specification (e.g. level of material recyclability, level usage of recycled material, toxicity of manufacturing processes) and some criterion are mandatory. The legitimacy of environmental experts is recognised. However, the ponderation factor of environmental criterion is less important than cost or mechanical design criterion. Therefore, environmental criterion are not considered as equally important than the other criterion by product designers. They tend to slow down the information exchange process between them and the environmental experts, which reduces the chance of environmental improvements before design choices are settled. The environmental criterion are new, therefore, product designers struggle to establish a detailed link between their own design choices and the environmental consequence of their choices (even if they roughly understand that design choices have an effect on the environmental performance of the product). To 
establish this link, environmental experts have created a tool for product designers that delivers design choices related guidelines in line with environmental aspects of the product.

- Technical information exchange: information exchanges between product designers and environmental experts are formal (by email and table) and informal (oral). A considerable amount of energy and time is spent by environmental experts to find the information about the product being designed that they require to analise the environmental impacts of design choices. Therefore, information exchanges are non systematic. The "guideline tool" mentioned above is not supported by any existing tool (such as the PLM software), so is hardly used systematically by product designers (no link with their own software environment).

\subsection{Case studies results: during FESTivE stages $A$ and $B$}

Results have been gathered through a list of feedbacks from interviewees: Pros. and Cons. mentioned per sector of expertise (product designers and technology experts, IT developers, environmental experts), and using the Likert scales to estimate their agreement on each affirmative question (section 4.2) based on the validation criteria showed in Fig. 3.

Results of FESTivE stage A: technical. The prototype was codeveloped with a developer from the LSIS research centre and the researcher working on FESTivE. The prototype was based on real industrial data from Parkeon. Interviews and research action were conducted with interviewees from Parkeon before and after the development of the prototype.

Results of interviews and estimations show. (Likert scale: very bad, bad, neutral, good, very good; average based on all results):

- Easy to implement: good (mainly due to the use of Eclipse software by IT developers in Parkeon)

- Capacity to develop and easily update models (expert/developer): good

- Code modularity, capacity to develop the code little by little (incremental): good (mainly due to MDE)

- Time and cost development: subjective and contextualised estimation

The estimation of time and cost developments were based on feedbacks from developers, product designers and environmental expert. Cost and time developments of FESTivE were important at the beginning, while the time spent by information exchange was similar to usual (without FESTivE). However, after a couple of design processes the majority of model developments were done and the information exchanges were fast.

Results of FESTivE stage B: in practice. Mock-ups and cartographies were developed by three researchers based on real data gathered by interviews conducted in Quiksilver. Interviews and research action were conducted with interviewees from Quiksilver and Parkeon before and after the development of the cartographies and mock-up. Results of interviews and estimations show (Likert scale: very bad, bad, neutral, good, very good; average based on all results):

- Practical in use (integration - ergonomic): good

- Link between product design parameters and environmental expert parameters: good

- Formalisation of data: good

- Time spent per information exchange: very good

- Reactivity: very good

- Flexibility in choosing tools adapted to the knowledge of the user: very good
Feedback from interviews and discussions showed that in the situation where FESTivE has been used, reactivity per design iteration increases and the time spent per iteration is reduced. Therefore, product designers feel that they are more equipped to anticipate environmental expert needs on next iterations (cf. Fig. 4).

In addition, the environmental expert highlighted the benefits of FESTivE method in terms of formalising data and therefore capitalising information.

Complementary and adding more controversy to those estimations, feedbacks from each expertise have been gathered during interviews. They are presented per category of expertise interviewed during both case studies.

Pros. and Cons. feedbacks from the product designers and technology experts:

- Cons.: FESTivE could be difficult to use if transformations between models are complex; should avoid automatic information exchanges without direct control of what is sent; should give the possibility to unlock an information exchange engaged in a transformation process that waits for another information to be sent (sequencing).

- Pros.: FESTivE allows the links between data related to different expertise to be kept; information to be shared and to be defined; the interaction of information to be managed, due to a management of the information in each expert software; transformations and models to be incrementally enriched; simple information exchanges; direct physical confrontations with other experts to be avoided when exchanging routine informations; a minimum of common knowledge related to design parameters between them and environmental experts to be co-built; rapid reactivity on short iterations to occur between them and environmental experts; the last minute design change management to be avoided or better anticipated (taking into account the increase of pressure of design delays along the design process). Similar mechanisms as used in the FESTivE method could be used for a Redesign to Cost purpose.

Pros. and Cons. Feedbacks from the IT developer of the company:

- Cons.: the proposition is quite theoretical; return on investment is function of the amount of transformation to create.

- Pros.: allows product designers and experts to exchange feedback as early as possible during design; the iterative aspect involved in the FESTivE process is to be put up front: information exchanges on rapid, short and iterative loops are very positive; allows some freedom in the choice of the environmental assessment tool; incremental evolution of the information exchange; there is not necessary any psychological retrain

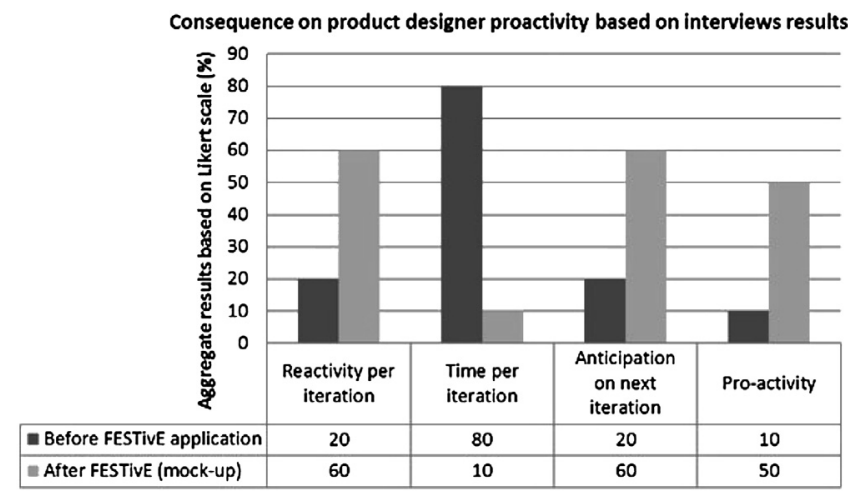

Fig. 4. FESTivE stage B case studies results. 
to have on the fact that informations are being published in models, using FESTivE, experts are more likely to focus on informations they should be dealing with; FESTivE answers to a real need.

Pros. and Cons. Feedbacks from environmental experts:

- Cons.: informations are handled by the IT developer; there is a risk to be in the dark without having any terminal to visualise the statute of information being exchanged; there is a lack of visibility on the effort to be given in order to manage the evolution of the system provided by the use of FESTivE; may be complex to manage environmental assessment result feedbacks related to each design choice and each expertise; the full FESTivE process is relatively complex to carry on.

- Pros.: freedom and transparency are given to each expert in the choice of software that best fits his existing tool lot (more flexibility); more transparency are given in the data exchanged and used; incremental and precise implementation of the metamodel to connect for supporting the information exchange; the method reduces the overall financial investment and the labour costs; FESTivE supports guidance of environmental objectives during the project duration.

\section{Discussion: synthesis of validation and limitations of the proposition}

\subsection{Validation synthesis of the paper proposition}

Case study results shows that stage A of FESTivE can be technically applied in different industrial contexts. Models can be easily developed and updated little by little. The code offers a good modularity when programming. However, transformation models can present some complexity in their definition and when managing their sequencing. The method allows product designers and environmental experts to decide at their own pace which federation model development should be undertaken and when. Information exchanges based on model federation coexist with usual information exchanges in the company. Even if the rapidity of the information exchange could significantly reduce labour costs during design, the overall return on investment would be function of the amount and complexity of the transformations created.

Case study results on stage B of FESTivE show that once stage A developments are done, information exchanges between product designers and environmental experts are fast and based on formalised data. Product designers and environmental experts gain flexibility in the choice of suitable tools available in the library of tools and models. In addition product designer and environmental expert reactivity per iteration increases. They are more equipped to anticipate information needed to others for the next iterations. Literature definition of proactivity shows that the capacity to anticipate is a factor that increases proactivity between product designers and environmental experts.

Those first results show that use of FESTivE supports collaboration between product designers and the environmental expert during the design process within various contexts. Furthermore developments are needed to develop a terminal to visualise and manage the statute of the information being exchanged. Discussions about the access to this terminal (IT developers v.s. product designers and environmental experts) should be carried on.

The specific status of the IT developer during design should be carefully considered to furthermore investigate the effect of FESTivE application in industry. When using FESTivE product designers and IT developers are sharing knowledge in a privileged relationship. Letting the IT developer focuses more on product designers' needs would require the company to adapt its culture to this new way of doing (FESTivE). This might involve reorganisation and people management changes in the company.

\subsection{Limitations of paper proposition validation}

The chosen validation method of existing methods (REX, theoretical, etc.), were adapted to the nature of the proposition (involving people and the culture of the company) in a medium term period of validation. Experiments were based on industrial case studies evaluating the proposal objectively with Likert scale and subjectively contextualised through discussion feedback. In design research the subject is part of the case study, which is why validation is also supported by feedbacks, pros, cons, of each interviewee. For further research, some suggestions are made to improve the validation of the proposition.

The validation method follows a bottom-up approach: from concepts analysis to generalisation of concepts. However, industrial case studies are limited in number. There are only two different industrial contexts involved. In addition, the prototype and mockups were based on real data but developed in a research laboratory. The next stage of this research would be to involve more companies for the trial of a $100 \%$ internal use of FESTivE by product designers, environmental experts and IT developers. Lastly, results show that use of FESTivE supported collaboration between product designers and the environmental expert during the design process within various contexts; however, there is no proof that it improves and increases the number of ecodesigned products developed by the company. This would involve long term measurements, which is a common difficulty in design research.

To conclude, this paper formalises a first step in using model federation supported by MDE for facilitating environmental expert and product designer information, when integrating environmental concerns in design. It opens new opportunities for software developers currently searching interoperability solutions between life cycle analysis software and product designer software.

\section{Contribution and perspectives}

This paper proposes a method (FESTivE) to improve collaboration between product designers and environmental experts during the design process within various industrial contexts. The literature review highlighted three major issues and the article proposes the FESTivE method to address them. The FESTivE method is presented in two major stages and is based on model federation, using model driven engineering techniques. Presented to industries using FESTivE in two case studies showed that product designers and environmental experts were more equipped to:

- Adapt themselves to different ecodesign project contexts, by being able to find proper tools, supported with a flexible IT system;

- Detect and exchange available information in a dynamic way (fast and accurately);

- Improve the link between the design and environment parameters they are dealing with, as early as possible and continuously during the design process.

This research contributes to the specific needs of industries. It emphasises the importance of improving the knowledge of semantic links between data used by product designers that have major consequences for the environmental aspect of products being designed.

This research opens different perspectives on a short to medium term basis. For instance, increasing knowledge about existing 
semantic links between the data (e.g. used by an expert) and the environmental parameter linked with this data could be a major area of research to be conducted in short term. Part of this research would include working on semantic links between dynamic Life Cycle Inventories (LCI) and dynamic LCA (Laratte et al., 2012). This research would also seek to develop the use of FESTivE method by product designers during the early design stage: providing support for early design concept adoption by stakeholders. The relevant medium term research perspective based on regular feedback of the use of FESTivE method by product designers would be to analyse the links between environmental assessment uncertainty and knowledge maturity of product designers during the ecodesign processes. For instance, the level of data completion could be dynamically anticipated, forecasting the quality of the data and the assessment conducted. Some knowledge transformation rules could be established based on common physics laws for instance. Meta-models could therefore be shared within industries in an open access platform, as mentioned in other contributions relating to the application of model federation in design process (Iraqi and Roucoules, 2013).

\section{References}

Barth, A., Caillaud, E., Rose, B., 2011. How to validate research in engineering design ?. In: International Conference on Engineering Design ICED11, Denmark, pp. $1-11$.

Blessing, L.T.M., Chakrabarti, A., 2009. DRM, a Design Research Methodology. Springer-Verlag, London.

Brissaud, D., Tichkiewitch, S., Zwolinski, P., 2006. Innovation in Life Cycle Enginnering and Sustainable Development. Springer.

Buclet, N., 2011. Ecologie industrielle et territoriale, stratgies locales pour un dveloppement durable, Septentrion. Presses Universitaires, France.

Buclet, N., 2011. Le territoire, entre libert et durabilit. Presse Universitaire de France, France.

Crutzen, P.J., 2002. The effects of industrial and agricultural practices on atmospheric chemistry and climate during the anthropocene. J. Environ. Sci. Health Part Toxic Hazard. Subst. Environ. Eng. 37 (4), 423-424.

Dewulf, W., 2003. A Pro-active Approach to Ecodesign: Methods and Tools, Ecodesign in Central America. Katholieke Universiteit Leuven, Leuven.

Duflou, J., Dewulf, W., Sas, P., Vanherck, P., 2003. Pro-active life cycle engineering support tools original research article. CIRP Ann. Manuf. Technol. 52 (1), 29-32.

Erkman, S., 2002. The Recent History of Industrial Ecology. In: A Handbook of Industrial Ecology, vol. 27.

Favre, J.-M., Estublier, J., Blay-Fornarino, M., 2006. In: Lavoisier (Ed.), L'ingenierie dirigee par les modeles, au-dela du MDA. Hermes Science Publications.

Highsmith, J., Cockburn, A., 2001. Agile software development: the business of innovation. Computer 34 (9), 120-127.

Hubka, V., Eder, W.E., 1996. Design Science: Introduction to Needs, Scope and Organization of Engineering Design Knowledge. Springer.

Iraqi-Houssaini, M., Kleiner, M., Roucoules, L., 2011. Model-based (Mechanical) Product Design, Model Driven Engineering Languages and Systems. Springer, pp. 548-562.

Iraqi, M., Kleiner, M., Roucoules, L., 2012. Tools interoperability in engineering design using model-based engineering. In: Proceedings of the 11th Biennial Conference on Engineering Systems Design and Analysis ESDA2012, France.

Iraqi, M., Roucoules, L., 2013. From functional analysis to CAD modelling based on knowledge transformation driven by the design process. In: PLM13 Conference Nantes, France, pp. 1-10.

ISO, 2006. ISO 14040 Environmental Management-Life Cycle Assessment-Principles and Framework.

ISO, 2006. ISO 14044 Environmental Management-Life Cycle AssessmentRequirements and Guidelines.

ISO, 2002. ISO/TR 14062 Environmental Management-integrating Environmental Aspects into Product Design and Development.

ISO, 1998. 14258-Concepts and Rules for Enterprise Models.
Joore, P., 2012. A multilevel design model clarifying the mutual relationship between new products and societal change processes. book chapter of. In: Reinders, A.H., Diehl, J.C., Brezet, H. (Eds.), The Power of Design: Product Innovation in Sustainable Energy Technologies. John Wiley and Sons pp. 21-138. chap. 2.10 .

Kota, S., Chakrabarti, A., 2007. Development of a platform for supporting design for environment, international conference on engineering design. In: ICED'07, Paris.

Laratte, B., Bertrand, G., Birregah, B., 2012. Dynamic environmental assessment: scenarios, foresight and challenges. chap. 118. In: Matsumoto, Mitsutaka Umeda, Yasushi, Masui, Keijiro, Fukushige, Shinichi (Eds.), Design for Innovative Value Towards a Sustainable Society. Springer, Netherlands, pp. 615-618.

Lewandowska, A., Kurczewski, P., 2010. ISO 14062 in theory and practiceecodesign procedure. Part 1: structure and theory. Int. J. Life Cycle Assess. 15 (8), 769-776.

Lozano Garca, F.J., Kevany, K., Huisingh, D., 2006. Sustainability in higher education: what is happening? J. Clean. Prod. 14 (9 to 11), 757-760.

Mathieux, F., et al., 2005. Opportunities and challenges for connecting environmental assessment tools and CAD software. In: Innovation by Life Cycle Management LCM Barcelona.

Millet, D., 2003. Intgration de l'environnement en conception, l'entreprise et le dveloppement durable". Hermes Science, France.

Morin, E., 2002. La Voie: Pour l'Avenir de L'Humanite, France.

Navarro, G., Rizo, T.C., Ceca, S.B., Collado Ruiz, M.J., 2005. Ecodesign function and form. classification of ecodesign tools according to their functional aspects". In: Proceeding of the ICED 05: 15th International Conference on Engineering Design: Engineering Design and the Global Economy, Engineers Australia.

Pahl, G., Beitz, W., 1996. Engineering Design: a Systematic Approac". London.

Reyes, T., Millet, D., Joan, M., 2007. Development of ecodesign integration trajectories: two surveys and LCA case study with a power distribution product study with a power distribution product. In: Proceedings of the International Conference on Engineering Design, ICED'07. Paris.

Riel, A., Tichkiewitch, S., Messnarz, R., 2010. Qualification and certification for the competitive edge in integrated design. CIRP J. Manuf. Sci. Technol. 2, 279-289.

Rio, M. Reyes, T., Roucoules, L., 2013. Toward proactive (eco)design process: modeling information transformations among designers activities. J. Clean. Prod. 39 (0), 105-116

Rio, M., Reyes, T., Roucoules, L., 2011. Toward proactive eco-design based on engineering and eco-desiner's software interface modeling. In: International Conference on Engineering Design ICED11.

Rockstrom, J., 2009. A safe operating space for humanity. Nature 461 (24).

Roucoules, L., Tichkiewitch, S., 2000. CoDE: a cooperative design environment-a new generation of CAD systems. Concurr. Eng. 8 (4), 263-280.

Saaty, T.L., 1980. The Analytic Hierarchy Process: Planning, Priority Settings, Resource Allocation. McGraw-Hill International Book Co.

Theret, J.-P., Zwolinski, P., Mathieux, F., 2011. Integrating CAD, PLM and LCA: a new architecture and integration proposal. In: Proceedings of the International Conference on Renewable Energy and Eco-design in Electrical Engineering, Lille, France.

Tyl, B., Legardeur, J., Millet, D., Vallet, F., 2010. Stimulate creative ideas generation for eco-innovation: an experimentation to compare eco-design and creativity tools. In: Proceedings of IDMME - Virtual Concept, Bordeaux, France, vol. 3 pp. 1-6.

Vallet, F., Messaadia, M., Eynard, B., 2010. Sustainability Requirements Deployment in Product-process Eco-design. IMS2020, pp. 1-18.

Vallet, F., Millet, D., Eynard, B., 2010. How ecodesign tools are really used- requirements list for a context-related ecodesign tool. In: Proceedings of the CIRP 2010 Conference.

Vallet, F., Millet, D., Eynard, B., 2013. Understanding needs in eco-design learning for novice designers. In: Chakrabarti, A. (Ed.), CIRP Design 2012. Springer, London, pp. 409-418.

Wiggum, K.S., 2004. Human and Ecological Problem Solving Through Radica Design Thinking. Department of Product Design Engineering, Faculty of Engineering Science and Technology, Norwegian University of Science and Technology, Trondheim.

Zhang, F., Rio, M., Allais, R., Zwolinski, P., Reyes, T., Roucoules, L., Mercier-Laurent, E. Buclet, N., 2013. Toward a systemic navigation framework to integrate sustainable development into the company. J. Clean. Prod. 54 (1), 199-214. 